\title{
Predictive Factors of Attrition in a Cohort of Alzheimer Disease Patients
}

\author{
The REAL.FR Study
}

\author{
Nicola Coley ${ }^{a, b}$ Virginie Gardette ${ }^{a, b}$ Olivier Toulza ${ }^{c}$ \\ Sophie Gillette-Guyonnet ${ }^{a, c}$ Christelle Cantet ${ }^{a, c}$ Fati Nourhashemi ${ }^{a, c}$ \\ Sandrine Andrieu ${ }^{\mathrm{a}-\mathrm{c}}$ Alain Grand ${ }^{\mathrm{a}, \mathrm{b}}$ Bruno Vellas ${ }^{\mathrm{a}, \mathrm{c}}$ \\ a Inserm, U558, University of Toulouse III; ${ }^{b}$ Department of Epidemiology and Public Health and \\ 'Gerontopole, Department of Geriatric Medicine, CHU Toulouse, Toulouse, France
}

\section{Key Words}

Attrition • Bias • Dropouts • Alzheimer's disease $\cdot$

Longitudinal study $\cdot$ Cohort study $\cdot$ Caregiver

\begin{abstract}
Background: Attrition, i.e. patient dropout, can threaten the validity of results in longitudinal studies. The aim of this study was to identify patient and caregiver factors predictive of attrition in a cohort of Alzheimer disease (AD) patients. Methods: 686 patients with mild to moderate AD were included in the multicenter prospective REAL.FR study. Standardized gerontological evaluations were carried out twice yearly. Factors associated with attrition were assessed by survival analysis using a Cox proportional hazard model. $R \boldsymbol{e}$ sults: After 2 years, 278 (40.5\%) patients had dropped out. Causes of attrition included refusal (20.9\%), death (20.1\%), institutionalization (19.8\%), and loss to follow-up (19.8\%). Attrition rates between each 6-month wave were constant at $12 \%$. After adjustment, several independent factors remained associated with attrition: patients cared for by an unrelated caregiver [HR 1.7; 95\% Cl (1.08-2.59)], loss of autonomy $[H R=1.37 ;(1.03-1.82)]$, increasing caregiver burden $[H R=1.014 ;(1.005-1.022)]$, use of cholinesterase inhibitors $[H R=0.40 ;(0.27-0.59)]$, use of 1 to 3 other types of medication $[H R=0.57 ;(0.36-0.89)]$. Conclusions: The identification
\end{abstract}

of both patient and caregiver factors predictive of attrition is of particular interest for the development and targeting of attrition prevention strategies. In patients with chronic diseases, particular attention should be paid to caregiver wellbeing to limit attrition.

Copyright ๑ 2008 S. Karger AG, Basel

\section{Introduction}

Prognosis studies provide useful insights into the natural history of a disorder, as well as examining associations between risk factors and health outcomes in patient populations. However, the quality of the results of such studies may be jeopardized by various types of bias, including attrition [1]. Attrition, defined as premature study dropout during follow-up, is a frequently observed phenomenon which can threaten the validity of results in longitudinal studies, regardless of the study population involved. Attrition systematically reduces statistical power by reducing the size of the study population, and it can introduce bias if dropouts differ from subjects remaining in the study [2]. It is important to identify factors associated with attrition so that subjects at high risk of attrition can be identified and targeted in order to limit the impact of this phenomenon. The analysis of factors associated

\section{KARGER}

Fax +4161306 1234 E-Mail karger@karger.ch www.karger.com
(C) 2008 S. Karger AG, Basel

0251-5350/08/0312-0069\$24.50/0

Accessible online at:

www.karger.com/ned
Nicola Coley

Inserm U558, Faculté de médicine

37, allées Jules Guesde, FR-31073 Toulouse (France)

Tel. +33 562145907 ext. 43 52, Fax +33562 264240

E-Mail nicolacoley@hotmail.com 
with attrition can also help to determine whether the attrition is selective, and whether it affects the generalizability of findings [3].

There are several types of attrition, including death, refusal, contact failure and inability to respond. In elderly populations, death may be an important source of attrition $[3,4]$. Attrition rates may vary across different studies involving elderly participants according to the chosen definition of attrition, as well as design (observational or interventional study, length of follow-up, frequency and type of study contacts, use of attrition prevention strategies such as tracking or bonding) or participant (age, comorbidities, frailty, autonomy) characteristics $[5,6]$.

There may be a particularly high risk of attrition in cohorts of elderly subjects with cognitive impairment, such as mild cognitive impairment or Alzheimer disease (AD), as has been observed in randomized controlled trials: for example, $20-30 \%$ after 6 months to 1 year of follow-up [6]. There is less data available regarding attrition in long-term longitudinal studies of AD patients [7-9].

Attrition in research involving cognitively impaired elderly patients may be particularly affected by death, refusals to participate (by the patient and/or his or her family) and loss of autonomy. Furthermore, the follow-up of elderly subjects with $\mathrm{AD}$ may also require the active participation of a caregiver, for example to accompany the participant to study visits, or to carry out assessments of the participant.

Very few studies have specifically examined factors associated with attrition in elderly cognitively impaired subjects [10,11], and caregiver-related factors have never been assessed.

The main objective of this study was to identify and describe both patient- and caregiver-related factors associated with attrition in a cohort of elderly patients with $\mathrm{AD}$ after 2 years of follow-up. Our hypothesis was that caregivers may be an independent source of attrition.

\section{Population and Methods}

The REAL.FR study is a multicenter prospective study of AD patients which began in 2000, with the objectives of studying the natural history of AD and its management. A detailed protocol of the study has been published elsewhere [12]. This study was approved by the Institutional Review Boards of each participating university.

Briefly, REAL.FR was carried out in 16 university hospitals in France. The study population consisted of ambulatory community dwelling AD patients enrolled during a hospital consultation. At the time of enrolment, subjects met DSM-IV and NINCDS-
ADRDA (National Institute of Neurological and Communicative Diseases and Stroke/Alzheimer Disease and Related Association) criteria for AD [13, 14], and presented a Mini Mental State Examination (MMSE) [15] score between 10 and 26. All patients were required to be looked after by an informal caregiver.

At inclusion and twice yearly, patients underwent a standardized gerontological evaluation (MMSE [15], Alzheimer's Disease Assessment Scale-cognitive subscale [16], Clinical Dementia Rating [17], Activities of Daily Living (ADL) [18], Instrumental Activities of Daily Living [19], Neuropsychiatric Inventory (NPI) [20], and Mini Nutritional Assessment (MNA) [21]). Socioeconomic data were also collected. Furthermore, the caregiver-patient relationship and the level of caregiver burden, assessed using the Zarit Burden Interview [22], were recorded. This scale uses 22 items evaluated on a 5 -point Likert scale. Scores range from 0 to 88 , with a score greater than 20 representing some level of burden. Events such as hospitalization, institutionalization, and treatment changes were noted. Date of death or admission to a nursing home was obtained from the caregiver, a family member or some other qualified informant.

Subjects who missed follow-up visits were contacted by telephone, and mail if necessary, in order to determine the reason for nonattendance (fig. 1). In the case of refusal, a second visit was offered to the caregiver, with or without the patient, and if this was not possible or was refused, a short questionnaire was administered by telephone or at the patient's/caregiver's home to assess the patient's status [mobility, autonomy, cognitive functions, occurrence of medical event(s), change in the patient's entourage and cholinesterase inhibitor (ChEI) use]. For real losses to followup, the general practitioner and the second caregiver were telephoned in order to obtain data regarding the patient.

Causes of attrition were classified as follows: patient or family/ caregiver refusal, death, institutionalization if it prevented the patient from attending study visits, difficult to locate (i.e. lost to follow-up), other (relocation, patient medical problems, worsened health preventing continued participation, caregiver problems, transfer to another study center, others).

Attrition was considered as a binary dependent variable. The outcome 'length of follow-up/time to dropout' was documented for each subject, and defined as the difference between the date of inclusion and the censored date (attrition whatever its cause or final 2-year endpoint).

In the statistical analysis of the study population at inclusion, mean values \pm standard deviation (SD) and proportions were used to describe quantitative and qualitative variables, respectively. A survival analysis was performed to identify baseline factors associated with the time of dropout, using relative hazard ratios and $95 \%$ confidence intervals (CI). The time variable was the duration of follow-up, with attrition considered as failure. Each variable was tested using log-rank tests. A multivariate analysis was then performed using a statistical significance level $<0.25$ in the bivariate survival analysis. A Cox proportional hazard model was also used, with adjustment for the center (nonproportionality stratification [23]), and backward stepwise regression. Tests based on interaction with time were used to assert the proportional hazards assumption. Statistical interactions were verified. $p$ values were based on two-sided tests and considered statistically significant if $\mathrm{p}<0.05$.

All analyses were performed using SAS software (version 9.1, SAS institute Inc., Cary, N.C., USA). 


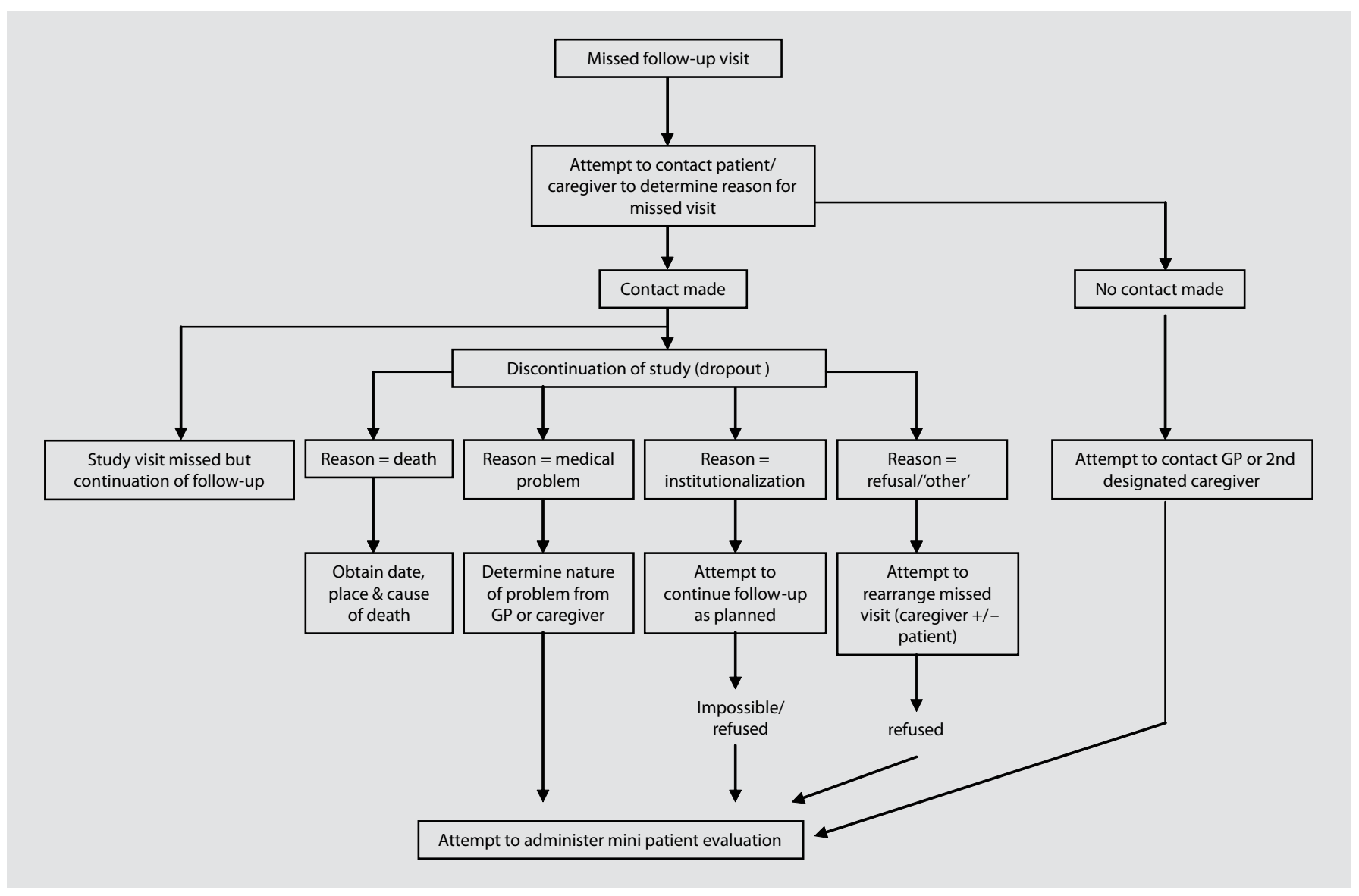

Fig. 1. Contact procedures after missed follow-up visits for the 686 patients enrolled in the REAL.FR study.

\section{Results}

A total of 686 patients were included in the REAL.FR study between 2000 and 2002, and followed for an average of 2 years (954.34 person-years, median duration of follow-up 651 days). The demographic and biological characteristics of the patients at baseline are summarized in table 1 . At inclusion, the patients, who were mostly recruited from geriatric departments (83.4\%), were aged $77.9 \pm 7$ years. Although they had been diagnosed with $\mathrm{AD}$ for a mean of $13.2 \pm 13.4$ months (mean age at diagnosis $76.8 \pm 7$ years), many patients were still at a stage of moderate cognitive impairment, with $54 \%$ completely independent for basic activities of daily living (ADL score). $87.6 \%$ had at least one behavioral disturbance according to the NPI.

The proportion of patients with 2 or more comorbidities was $40.7 \%$. The mean MNA score was $24 \pm 3$, and one third of the patients were at risk of malnutrition
(MNA $\leq 23.5)$. Following the baseline visit, $89 \%(n=611)$ of patients in the cohort were treated with a ChEI $(87.6 \%$ were treated before this visit, and 76 patients were prescribed a ChEI for the first time during this visit). Although all patients were required to have an informal (i.e. nonprofessional) caregiver, more than a quarter lived alone, regardless of dementia severity. $60 \%$ of patients had a female caregiver, most often the wife or daughter. At inclusion, the mean caregiver score on the Zarit scale was $22.6 \pm 16$, and $50 \%$ of caregivers reported some degree of burden (Zarit $>20$ ). At this early stage of the disease, the level of health care support remained low: 20\% of patients had nursing help, either at home or in a private practice, $44 \%$ had a home-help, and only $2 \%$ used day care facilities.

Of the 686 patients, 278 had dropped out by 2 years of follow-up, representing $40.5 \%$ of the initial cohort (fig. 2) and an incidence rate of $29.13 / 100$ person years (95\% CI: 25.70-32.56). 
Table 1. Baseline demographic and clinical characteristics of the REAL.FR cohort

\begin{tabular}{|c|c|c|c|c|}
\hline & $\begin{array}{l}\text { All patients } \\
(\mathrm{n}=686)\end{array}$ & $\begin{array}{l}\text { Patients remai- } \\
\text { ning in the study } \\
(n=408)\end{array}$ & $\begin{array}{l}\text { Dropouts } \\
(\mathrm{n}=278)\end{array}$ & $\mathrm{p}^{\mathrm{a}}$ \\
\hline Mean age $\pm S D$, years & $77.9 \pm 6.8$ & $77.1 \pm 6.7$ & $79.0 \pm 6.8$ & $<0.001$ \\
\hline Sex, \% & & & & 0.183 \\
\hline Male & 28.9 & 27.0 & 31.6 & \\
\hline Female & 71.1 & 73.0 & 68.4 & \\
\hline \multicolumn{5}{|l|}{ Number of comorbidities, \% } \\
\hline 0 & 24.2 & 29.2 & 17.0 & $<0.001$ \\
\hline 1 & 35.1 & 36.7 & 32.8 & \\
\hline$\geq 2$ & 40.7 & 34.1 & 50.2 & \\
\hline ChEI use ${ }^{\mathrm{b}}, \%$ & 89.1 & 93.1 & 83.1 & $<0.001$ \\
\hline MMSE & $20.0 \pm 4.2$ & $20.50 \pm 4.0$ & $19.3 \pm 4.4$ & $<0.001$ \\
\hline ADAS-cog & $17.9 \pm 8.2$ & $16.7 \pm 7.3$ & $19.5 \pm 9.1$ & $<0.001^{\mathrm{c}}$ \\
\hline Total ADL (out of 6) & $5.4 \pm 0.9$ & $5.6 \pm 0.7$ & $5.2 \pm 1.1$ & $<0.001^{\mathrm{d}}$ \\
\hline \multicolumn{5}{|l|}{ IADL, $\%$} \\
\hline$\leq 2$ & 49.2 & 57.4 & 37.3 & $<0.001$ \\
\hline$>2$ & 50.8 & 42.6 & 62.7 & \\
\hline CDR, \% & & & & $<0.001$ \\
\hline 0.5 & 34.2 & 40.3 & 25.2 & \\
\hline 1 & 42.1 & 41.6 & 42.8 & \\
\hline 2 or 3 & 23.7 & 18.1 & 32.0 & \\
\hline NPI frequency $\times$ severity & $15.3 \pm 15.3$ & $14.4 \pm 14.1$ & $16.7 \pm 16.9$ & $0.126^{\mathrm{e}}$ \\
\hline MNA $\leq 23.5, \%$ & 33.2 & 29.2 & 39.1 & 0.008 \\
\hline Medical assistance ${ }^{\mathrm{f}}, \%$ & 68.2 & 67.0 & 70.0 & 0.415 \\
\hline Non-medical assistance $\mathrm{g}, \%$ & 50.5 & 47.9 & 54.2 & 0.105 \\
\hline \multicolumn{5}{|l|}{ Level of education, $\%$} \\
\hline Technical/high school certificate or higher & 20.1 & 20.5 & 19.6 & 0.250 \\
\hline Early secondary education & 22.3 & 23.2 & 21.0 & \\
\hline Primary school certificate & 36.3 & 33.3 & 40.6 & \\
\hline Elementary or illiterate & 21.3 & 23.0 & 18.8 & \\
\hline \multicolumn{5}{|l|}{ Caregiver status and patient living } \\
\hline arrangements, $\%$ & & & & 0.002 \\
\hline Spouse & 53.4 & 57.1 & 47.9 & \\
\hline Child, noncohabiting ${ }^{\mathrm{h}}$ & 21.6 & 23.0 & 19.4 & \\
\hline Child, cohabiting & 16.0 & 12.5 & 21.2 & \\
\hline Other & 9.0 & 7.4 & 11.5 & \\
\hline \multicolumn{5}{|l|}{ Caregiver sex, \% } \\
\hline Female & 59.3 & 56.0 & 64.1 & 0.034 \\
\hline Caregiver age, years & $64.7 \pm 13.2$ & $65.2 \pm 13.3$ & $63.9 \pm 13.0$ & 0.214 \\
\hline Zarit & $22.6 \pm 15.9$ & $21.4 \pm 14.8$ & $24.4 \pm 17.2$ & $0.117^{\mathrm{e}}$ \\
\hline
\end{tabular}

ADAS-cog = Alzheimer Disease Assessment Scale-cognitive subscale; CDR = Clinical Dementia Rating; IADL $=$ Instrumental Activities of Daily Living.

${ }^{a}$ Between patients remaining in the study and dropouts. Unless stated otherwise, $p$ values are Student's t test for continuous variables, and $\chi^{2}$ tests for categorical variables.

${ }^{\mathrm{b}}$ Including patients who were prescribed a ChEI during the baseline visit.

${ }^{c}$ Test carried out after log transformation of variable.

${ }^{\mathrm{d}}$ Kruskal-Wallis test.

e Test carried out after square root transformation of variable.

${ }^{\mathrm{f}}$ Outpatient clinics, nurse home visits, speech therapist, physiotherapist, doctor.

g Home help, day center, nighttime assistance, daytime assistance, meals on wheels, personal alarm.

$\mathrm{h}$ 'Cohabiting' implies that the patient was not living alone, but it does not necessarily mean that the patient was living with the caregiver. 
Fig. 2. Total attrition between each 6month visit in the REAL.FR study, defined as the percentage of dropouts in relation to the number of patients remaining at the previous visit.
Fig. 3. Percentage of each specific cause of attrition in the REAL.FR study during each 6-month period of follow-up. The number of dropouts for each cause during waves 1, 2, 3, and 4 was, respectively: death $13,15,14,14$ (total $n=56)$; institutionalization 9, 15, 20, 11 (total $\mathrm{n}=55$ ); lost to follow-up 21, 13, 11, 10 (total $\mathrm{n}=55$ ); refusal $27,16,8,7$ (total $\mathrm{n}=58$ ); others $15,14,10$, 15 (total $\mathrm{n}=54$ ).
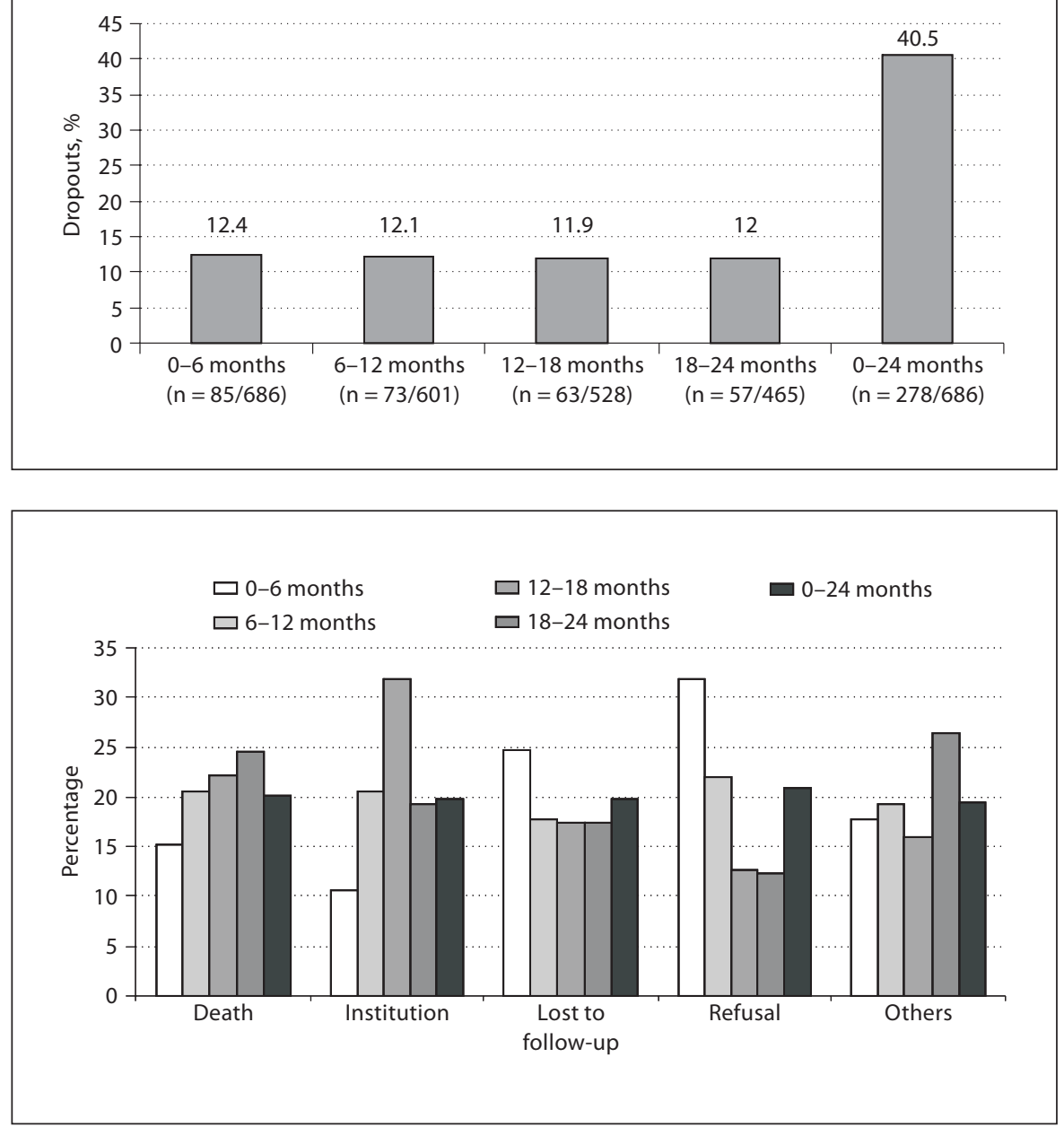

The frequency of dropouts between each wave (percentage of the remaining patients at the beginning of each wave) was constant at around $12 \%$, giving a cumulative rate of attrition of $12.4,23,32.2$ and $40.5 \%$ at $6,12,18$, and 24 months, respectively.

The reasons for dropout were refusal ( $\mathrm{n}=58 ; 20.86 \%)$, death $(n=56 ; 20.14 \%)$, nursing home placement $(n=55$; $19.78 \%)$, lost to follow-up ( $\mathrm{n}=55 ; 19.78 \%)$, moved house $(\mathrm{n}=15 ; 5.4 \%)$, medical problem $(\mathrm{n}=14 ; 5 \%)$, caregiver problem $(\mathrm{n}=7 ; 2.5 \%)$, follow-up in another center $(\mathrm{n}=6$; $2.16 \%)$, and other causes $(\mathrm{n}=12 ; 4.3 \%)$. Due to the small sample size, the last five causes were merged together in 'other causes' ( $\mathrm{n}=54 ; 19.42 \%)$.

Over the course of the study, the proportion of dropouts due to death and institutionalization tended to increase, the proportions of dropouts due to refusals and losses to follow-up appeared to be greatest in the first waves, and the proportion of patients dropping out due to other reasons remained relatively stable (fig. 3).

In the bivariate survival analysis, patient age was the only sociodemographic factor associated with an increased risk of attrition (table 2). In addition, patients with a history of cardiac problems, poorer nutritional status, and increasing cognitive or functional decline were at greater risk of dropping out of the study (table 3). Of the behavioral disturbances evaluated by the NPI, only hallucinations were found to be significantly associated with attrition.

Conversely, patients who were diagnosed with AD between 6 and 24 months ago were less likely to drop out than those diagnosed less than 3 months ago, as were those using a ChEI treatment or those using one to three other types of medication (as compared to no other types of medication). 
Table 2. Patient sociodemographic factors predictive of attrition in the bivariate survival analysis: relative hazard for time to dropout

\begin{tabular}{|c|c|c|c|}
\hline Inclusion parameters & HR & $95 \% \mathrm{CI}$ & $\mathrm{p}\left(\chi^{2}\right)$ \\
\hline \multicolumn{4}{|l|}{$\operatorname{Sex}(n=686)$} \\
\hline Female & 1 & - & - \\
\hline Male & 1.17 & $0.91-1.50$ & 0.229 \\
\hline Age, years $(n=686)$ & 1.03 & $1.02-1.05$ & $<0.001$ \\
\hline Level of education $(\mathrm{n}=681)$ & & & 0.250 \\
\hline Technical school, high school certificate or higher & 1 & - & - \\
\hline Early secondary education & 1.003 & $0.69-1.45$ & 0.986 \\
\hline Primary school certificate & 1.25 & $0.91-1.73$ & 0.172 \\
\hline Elementary or illiterate & 0.94 & $0.64-1.38$ & 0.763 \\
\hline Monthly household income, EUR $(n=680)$ & & & 0.174 \\
\hline$>2,287$ EUR & 1 & - & - \\
\hline 1,500-2,287 EUR & 1.30 & $0.93-1.82$ & 0.129 \\
\hline$<1,500$ EUR & 1.30 & $0.97-1.74$ & 0.077 \\
\hline
\end{tabular}

$\mathrm{HR}=$ Hazard ratio.

Table 3. Patient medical factors predictive of attrition in the bivariate survival analysis: relative hazard for time to dropout

\begin{tabular}{|c|c|c|c|}
\hline Inclusion parameters & HR & $95 \% \mathrm{CI}$ & $\mathrm{p}\left(\chi^{2}\right)$ \\
\hline Length of time since diagnosis $(n=686)$ & & & 0.006 \\
\hline$<3$ months & 1 & - & - \\
\hline 3-6 months & 0.80 & $0.52-1.21$ & 0.290 \\
\hline 6-12 months & 0.46 & $0.30-0.68$ & 0.0001 \\
\hline $12-24$ months & 0.65 & $0.45-0.94$ & 0.021 \\
\hline$\geq 24$ months & 0.79 & $0.55-1.14$ & 0.205 \\
\hline Not available & 0.74 & $0.49-1.12$ & 0.156 \\
\hline \multicolumn{3}{|l|}{$\begin{array}{l}\text { History of cardiac problems (atrial fibrillation/arrhythmia, } \\
\text { angina, MI, arteritis, congestive heart failure; } \mathrm{n}=686 \text { ) }\end{array}$} & 0.002 \\
\hline No & 1 & - & - \\
\hline Yes & 1.53 & $1.18-1.98$ & 0.001 \\
\hline Not available & 0.79 & $0.47-1.32$ & 0.366 \\
\hline \multicolumn{4}{|l|}{$\operatorname{MNA}(n=671)$} \\
\hline$>23.5$ & 1 & - & - \\
\hline$\leq 23.5$ & 1.40 & $1.10-1.78$ & 0.006 \\
\hline \multicolumn{4}{|l|}{ Medical assistance $^{1}(\mathrm{n}=667)$} \\
\hline No & 1 & - & - \\
\hline Yes & 1.13 & $0.87-1.47$ & 0.343 \\
\hline \multicolumn{4}{|l|}{ Non-medical assistance $^{2}(n=670)$} \\
\hline No & 1 & - & - \\
\hline Yes & 1.21 & $0.95-1.54$ & 0.117 \\
\hline \multicolumn{4}{|l|}{ ChEI (at end of first visit; $n=686$ ) } \\
\hline Not treated & 1 & - & - \\
\hline Treated & 0.46 & $0.34-0.63$ & $<0.001$ \\
\hline Number of other treatments $(n=684)$ & & & 0.040 \\
\hline 0 & 1 & - & - \\
\hline $1-3$ & 0.67 & $0.45-1.01$ & 0.059 \\
\hline$\geq 4$ & 0.89 & $0.60-1.33$ & 0.586 \\
\hline Total MMSE score $(\mathrm{n}=684)$ & 0.95 & $0.93-0.98$ & $<0.001$ \\
\hline Total ADAS-cog score $(n=673)$ & 1.03 & $1.01-1.04$ & $<0.001$ \\
\hline
\end{tabular}


Table 3 (continued)

\begin{tabular}{|c|c|c|c|}
\hline Inclusion parameters & $\mathrm{HR}$ & $95 \% \mathrm{CI}$ & $\mathrm{p}\left(\chi^{2}\right)$ \\
\hline CDR score $(n=682)$ & & & $<0.001$ \\
\hline 0.5 & 1 & - & - \\
\hline 1 & 1.50 & $1.11-2.01$ & 0.007 \\
\hline 2 or 3 & 2.13 & $1.56-2.91$ & $<0.001$ \\
\hline \multicolumn{4}{|c|}{ Number of ADL limitations $(n=686)$} \\
\hline 0 & 1 & - & - \\
\hline$\geq 1$ & 1.75 & $1.38-2.22$ & $<0.001$ \\
\hline \multicolumn{4}{|c|}{ Number of IADL (activities of daily living $/ 5 ; \mathrm{n}=665$ ) } \\
\hline$\leq 2$ & 1 & - & - \\
\hline$>2$ & 1.84 & $1.44-2.36$ & $<0.001$ \\
\hline \multicolumn{4}{|l|}{ NPI delusions $(n=686)$} \\
\hline Yes & 1.19 & $0.88-1.62$ & 0.256 \\
\hline \multicolumn{4}{|c|}{ NPI hallucinations $(\mathrm{n}=686)$} \\
\hline Yes & 1.87 & $1.26-2.77$ & 0.001 \\
\hline \multicolumn{4}{|c|}{ NPI agitation/aggression $(n=686)$} \\
\hline Yes & 1.02 & $0.80-1.30$ & 0.870 \\
\hline \multicolumn{4}{|c|}{ NPI depression/dysphoria $(n=686)$} \\
\hline Yes & 1.05 & $0.82-1.33$ & 0.704 \\
\hline \multicolumn{4}{|l|}{ NPI anxiety $(\mathrm{n}=686)$} \\
\hline Yes & 1.23 & $0.97-1.56$ & 0.083 \\
\hline \multicolumn{4}{|l|}{ NPI euphoria $(\mathrm{n}=686)$} \\
\hline Yes & 0.92 & $0.57-1.46$ & 0.711 \\
\hline \multicolumn{4}{|c|}{ NPI apathy/indifference $(n=686)$} \\
\hline Yes & 1.02 & $0.81-1.30$ & 0.843 \\
\hline \multicolumn{4}{|c|}{ NPI disinhibition $(\mathrm{n}=686)$} \\
\hline Yes & 1.36 & $0.97-1.92$ & 0.076 \\
\hline \multicolumn{4}{|c|}{ NPI irritability/lability $(\mathrm{n}=686)$} \\
\hline Yes & 0.95 & $0.75-1.22$ & 0.709 \\
\hline \multicolumn{4}{|c|}{ NPI aberrant motor activity $(n=686)$} \\
\hline Yes & 0.92 & $0.69-1.22$ & 0.552 \\
\hline \multicolumn{4}{|c|}{ NPI sleep disturbances $(n=686)$} \\
\hline Yes & 1.24 & $0.91-1.70$ & 0.168 \\
\hline \multicolumn{4}{|c|}{ NPI appetite abnormalities $(\mathrm{n}=685)$} \\
\hline Yes & 1.12 & $0.85-1.47$ & 0.437 \\
\hline
\end{tabular}

Caregiver status combined with living arrangements, and level of caregiver burden were also associated with higher attrition rates, while patients with a male caregiver were less likely to drop out of the study (table 4).

597 patients were included in the multivariate analysis, including 249 dropouts and the 348 remaining patients (table 5).

After adjustment for all variables found to be significant in the bivariate analysis, several independent factors remained associated with attrition: (i) AD patients cared for by an unrelated caregiver, i.e. not a spouse or child
[HR 1.7 (1.08-2.59); $\mathrm{p}=0.021$ ], (ii) a loss of autonomy $(\geq 1$ limitation) on the ADL scale [HR = 1.37 (1.03-1.82); $\mathrm{p}=$ 0.03], (iii) increasing caregiver Zarit burden score [HR = 1.014 (1.005-1.022); $\mathrm{p}=0.001]$, (iv) the use of a ChEI $[\mathrm{HR}=0.40(0.27-0.59) ; \mathrm{p}<0.0001]$, and (v) the use of one to three other types of medication compared to the use of no other types of medication $[\mathrm{HR}=0.57(0.36-0.89) ; \mathrm{p}=$ $0.01]$. 
Table 4. Caregiver factors predictive of attrition in the bivariate survival analysis: relative hazard for time to dropout

\begin{tabular}{|c|c|c|c|}
\hline Inclusion parameters & HR & $95 \% \mathrm{CI}$ & $\mathrm{p}\left(\chi^{2}\right)$ \\
\hline \multicolumn{4}{|l|}{ Caregiver sex $(n=678)$} \\
\hline Female & 1 & - & - \\
\hline Male & 0.78 & $0.61-0.99$ & 0.045 \\
\hline Caregiver age, years $(n=668)$ & 0.995 & $0.987-1.004$ & 0.313 \\
\hline Caregiver status and living arrangements $(n=686)$ & & & $<0.001$ \\
\hline Spouse & 1 & - & - \\
\hline Child, noncohabiting & 0.98 & $0.71-1.34$ & 0.882 \\
\hline Child, cohabiting & 1.75 & $1.29-2.38$ & $<0.001$ \\
\hline Other & 1.67 & $1.13-2.46$ & 0.009 \\
\hline Caregiver burden (Zarit score) $(\mathrm{n}=638)$ & 1.009 & $1.002-1.017$ & 0.015 \\
\hline
\end{tabular}

Table 5. Adjusted HR for characteristics associated with dropout in the Cox multivariate model stratified by center $(n=597)$

\begin{tabular}{lllr}
\hline & HR & $95 \%$ CI & $\mathrm{p}\left(\chi^{2}\right)$ \\
\hline $\begin{array}{l}\text { Caregiver status and living } \\
\quad \text { arrangements }\end{array}$ & & & \\
$\quad$ (ref.: spouse) & 1 & - & 0.023 \\
$\quad$ Child, noncohabiting & 0.78 & $0.54-1.12$ & 0.183 \\
$\quad$ Child, cohabiting & 1.04 & $0.72-1.50$ & 0.840 \\
$\quad$ Other & 1.67 & $1.08-2.59$ & 0.021 \\
$\begin{array}{l}\text { Number of ADL limitations: } \\
\quad 1 \text { vs. 0 }\end{array}$ & 1.37 & $1.03-1.82$ & 0.030 \\
$\quad \begin{array}{llll}\text { Total Zarit score } \\
\text { Use of ChEI (yes vs. no) }\end{array}$ & 0.40 & $0.27-0.59$ & $<0.001$ \\
Number of other treatments & & & 0.046 \\
$\quad$ (ref.: 0) & 1 & - & 0.0014 \\
$\quad$ 1-3 & 0.57 & $0.36-0.89$ & 0.014 \\
$\quad \geq 4$ & 0.68 & $0.43-1.06$ & 0.087 \\
\hline
\end{tabular}

The following variables were also introduced into initial models, but did not remain in the final model: MMSE, time elapsed since diagnosis, history of cardiac problems, CDR score, patient age, MNA, number of IADL limitations and hallucinations on NPI scale.

${ }^{1}$ At end of baseline visit.

\section{Discussion}

The aim of this study was to describe the level and causes of attrition after 2 years of follow-up in an AD longitudinal study. The attrition rate at 2 years was $41 \%$. Each cause of attrition (death, refusal, institutionalization, loss to follow-up, others) accounted for around $20 \%$, although the percentage of attrition attributable to each cause varied over time. The perceived burden of study visits may have discouraged certain patients from taking part, but those that were enrolled may have been more compliant, because this study was carried out in expert centers belonging to the national network of AD centers. In addition, the tracking methods used (fig. 1) may have limited the level of attrition.

The frequency of attrition in this study remained stable over time, at approximately $12 \%$ per 6 -month wave. This corresponds with the findings in some longitudinal studies of the elderly [24, 25], but is lower than others [26].

In the literature, there are relatively few longitudinal cohorts made up entirely of patients with $\mathrm{AD}$ or other forms of dementia. It is difficult to compare the rate of attrition in REAL.FR with all other AD longitudinal studies due to methodological differences, for example the definition of attrition and the study population, and the length of follow-up.

Of the three studies - LASER-AD [9], PREDICTORS study [7], Starkstein et al. [11] - that included death as a cause of attrition, the attrition rate appears to be lower than that observed in our study. In the Consortium to Establish a Registry for Alzheimer's Disease (CERAD) cohort, an attrition rate, excluding deaths, of $10.5 \%$ was observed amongst $978 \mathrm{AD}$ patients and 466 controls (often a spouse of the AD patient) in the first year of followup [10]. This rate is lower than the $19 \%$ observed after 1 year excluding death in REAL.FR, but the CERAD rate also includes control subjects.

The attrition rate in REAL.FR appears to be relatively high as compared to these other AD cohorts. This could be explained by methodological differences, for example, inclusion criteria concerning the severity of the disease [6]. In REAL.FR, death accounted for a smaller proportion of attrition than in other studies, indicating that other causes, such as loss of contact, institutionalization and medical problems were more prominent.

There are no guidelines regarding an acceptable level of attrition for longitudinal studies. Some authors have 
suggested that in randomized controlled trials, a loss to follow-up of $5 \%$ or less may be of little concern, but that losses of $20 \%$ or more may introduce considerable bias [27]. However, it may be unwise to set an explicit value to assess the risk for bias because the type of missing data must also be taken into account [28]. In practice, the occurrence of missing data is generally not random. Instead it is important to consider overlapping methodological issues and the direction of the potential bias on a case-bycase basis, and to determine whether or not dropout is associated with outcome (i.e. whether or not it is random) [29].

Studies of factors associated with attrition in AD cohorts have mainly been based on unadjusted analyses. Certain factors have been suggested, such as age, race, MMSE score, apathy, level of education, and type of dementia diagnosis $[10,11,30]$, but results are inconsistent across studies The findings of our study are in accordance with those reported in unadjusted analyses in the literature regarding population-based studies of elderly people for the role of age, and level of cognitive impairment [4].

In our multivariate analysis, patients with at least one limitation on the ADL scale had a risk of attrition that was 1.37 times higher than that of subjects with no limitations. Functional impairment may be a more important indicator of attrition than cognitive impairment. It may be more difficult for a caregiver to ensure attendance at study visits if the patient has functional impairment compared to cognitive impairment, as functional impairment may bring about more practical problems that the caregiver may have difficulties in overcoming.

Patients not using a ChEI were 2.5 times more likely to drop out than treated patients. The REAL.FR cohort was established in 2000 , meaning that a high proportion of subjects (89\% including those who were prescribed a ChEI during the baseline visit) were treated with ChEIs. The efficacy of ChEIs has been demonstrated for mild to moderate $\mathrm{AD}$ patients [31], so it is probable that treated patients are more likely to attend consultations in order to receive their medication, demonstrating a 'protective' effect of ChEI use on attrition.

An explanation for the non-use of ChEIs, apart from contraindications, could be that certain patients or their caregivers may refuse this type of treatment, perhaps because they have difficulties in accepting the pathology and in receiving medical care or advice. Such patients may therefore be less likely to remain in the study. $\mathrm{Pa}$ tients who were non-users of ChEIs at baseline may have previously been prescribed this medication and discon- tinued use because adverse drug reaction, which may affect the patients' or caregiver's confidence in the medical care being received, thus making them more likely to drop out of the study.

Patients using one to three types of medication other than ChEIs were found to be 1.75 times less likely to drop out of the study than those taking no other types of medication. The use of several types of medication may indicate that such patients are likely to receive increased medical care and attention, and we hypothesize they may present an increased compliance in medication use as well as in the study.

The remaining factors concern caregiver characteristics. Firstly, patients looked after by an unrelated caregiver (i.e. not a spouse or son/daughter) were found to be 1.7 times more likely to drop out of the study than those cared for by their spouse. This finding is in accordance with the results reported by Koss et al. [10], who noted that patients whose spouse was also included in the study (in their case as a control) were less likely to drop out than patients who did not have a spouse taking part.

We found that an increase of 1 point on the Zarit burden scale was associated with a $1.4 \%$ increase in the risk of attrition. To our knowledge, caregiver burden has never been examined as a determinant of attrition in studies of $\mathrm{AD}$ patients, although it has been found to be associated with institutionalization [32].

It is therefore important to be able to recognize and support exhausted caregivers in order to limit attrition in studies involving AD patients. For example, home assistance could be offered in order to reduce the caregiver burden. It has been suggested that caregivers play an important role in decision making regarding patient care, for example regarding medication use [33, 34], yet attrition prevention strategies have generally not been targeted towards caregivers [35]. It is important to convince the caregiver of the importance of regular medical care and attention for the patient. Even if the objective of natural history studies of $\mathrm{AD}$ is not to bring about a direct therapeutic benefit, regular medical assessment is likely to improve the overall management of the disease, thus providing potential benefits for both the patient and the caregiver. Attention should be paid to ensure that caregivers understand the benefits of taking part in such studies for both themselves and the $\mathrm{AD}$ patient.

In a recent systematic review of attrition in large population-based studies (i.e. not specifically focused on AD) Chatfield et al. [4] noted that in multivariate analyses, increasing age and poor cognitive performance were the only factors consistently associated with preventable at- 
trition (i.e. all types of attrition excluding death), but neither of these factors remained significant in our multivariate model. Our results may indicate that above a certain level of cognitive impairment, differences in the cognitive performance between patients may not affect attrition.

We have only identified one other study which has specifically analyzed factors associated with attrition in a cohort of $\mathrm{AD}$ patients in multivariate analyses. In this study, Koss et al. [10] reported three factors associated with attrition: non-white status, patients' spouse not enrolled in the study as a control, and inadequate involvement by the study site, but we did not assess these factors in our study as they were either not relevant or not available (due to national ethical guidelines). However, as in our study, patient age, level of education, and cognitive status were not associated with attrition.

We included death in our definition of attrition because our first objective was to identify subjects with missing data, whatever the cause. However, some authors exclude death as a cause of attrition. It is important to establish the factors associated with preventable attrition (i.e. all causes of attrition excluding death), and so we performed a sensitivity analysis using a multivariate model to establish predictive factors of preventable attrition in our study. The results were stable compared to the multivariate model presented above, except that caregiver status and living arrangements were no longer predictive of attrition (data not shown).

This study was an exploratory investigation into the causes of attrition and may have some limitations. Our population is probably unrepresentative of the entire $\mathrm{AD}$ population, because the patients included in our study had a diagnosis of probable $\mathrm{AD}$, and had been referred to an $\mathrm{AD}$ expert center.

Our results are largely dependent upon the definition of attrition used. Moreover, we only considered baseline factors as possible determinants of attrition and did not take into account the fact that some of these factors (e.g. caregiver burden, cognitive status) may have changed during the follow-up period.

Other studies have considered determinants of refusal, both before and during studies, rather than determinants of total attrition $[36,37]$. We could have examined subgroups of attrition, such as refusal, but our investigation was limited by the number of participants in our study.

Despite these limitations, this study of attrition is useful because the REAL.FR study involves one of the largest cohorts of AD patients so far studied, in which determinants of attrition have seldom been studied. Furthermore, this study is the first to examine caregiver characteristics as factors associated with attrition.

\section{Conclusion}

Long-term prognostic studies are necessary in order to improve our understanding of chronic diseases such as AD. Attrition may threaten the validity and generalizability of such studies, meaning that it is important to minimize dropouts. The identification of subjects who are at greater risk of dropping out is essential so that they can be specifically targeted by attrition prevention strategies, and closely monitored throughout the study. Caregiver factors, as well as those related to patients and study design may all influence attrition. Thus, particular attention should be paid to caregiver well-being to improve attrition.

\section{Acknowledgments}

This work was supported by a grant from the Clinical Research Hospital Program from the French Ministry of Health (PHRC No. 98-47N, PHRC No. 0101001).

\section{References}

1 Delgado-Rodriguez M, Llorca J: Bias. J Epidemiol Community Health 2004;58:635641.

2 Greenland S: Response and follow-up bias in cohort studies. Am J Epidemiol 1977;106: 184-187.

$\checkmark 3$ Deeg DJH: Attrition in longitudinal population studies: does it affect the generalizability of the findings? An introduction to the series. J Clin Epidemiol 2002;55:213-215.
4 Chatfield MD, Brayne CE, Matthews FE: A systematic literature review of attrition between waves in longitudinal studies in the elderly shows a consistent pattern of dropout between differing studies. J Clin Epidemiol 2005;58:13-19.

5 Schaie KW, Campbell RT, Meredith W, Rawlings SC: Methodological Issues in Aging Research. New York, Springer, 1988.
6 Gardette V, Coley N, Toulza O, Andrieu S: Attrition in geriatric research: how important is it and how should it be dealt with? J Nutr Health Aging 2007;11:265-271.

7 Holtzer R, Tang MX, Devanand DP, Albert SM, Wegesin DJ, Marder K, Bell K, Albert M, Brandt J, Stern Y: Psychopathological features in Alzheimer's disease: course and relationship with cognitive status. J Am Geriatr Soc 2003;51:953-960. 
-8 Regan C, Katona C, Walker Z, Hooper J, Donovan J, Livingston G: Relationship of vascular risk to the progression of Alzheimer disease. Neurology 2006;67:1357-1362.

$\checkmark 9$ Ryu SH, Katona C, Rive B, Livingston G: Persistence of and changes in neuropsychiatric symptoms in Alzheimer disease over 6 months: the LASER-AD study. Am J Geriatr Psychiatry 2005;13:976-983.

10 Koss E, Peterson B, Fillenbaum GG: Determinants of attrition in a natural history study of Alzheimer disease. Alzheimer Dis Assoc Disord 1999;13:209-215.

-11 Starkstein SE, Jorge R, Mizrahi R, Robinson RG: A prospective longitudinal study of apathy in Alzheimer's disease. J Neurol Neurosurg Psychiatry 2006;77:8-11.

12 Gillette-Guyonnet S, Nourhashemi F, Andrieu S, Cantet C, Micas M, Ousset PJ, Vellas B: The REAL.FR research program on Alzheimer's disease and its management: methods and preliminary results. J Nutr Health Aging 2003;7:91-96.

-13 McKhann G, Drachman D, Folstein M, Katzman R, Price D, Stadlan EM: Clinical diagnosis of Alzheimer's disease: report of the NINCDS-ADRDA Work Group under the auspices of Department of Health and $\mathrm{Hu}-$ man Services Task Force on Alzheimer's Disease. Neurology 1984;34:939-944.

14 American Psychiatric Association: Diagnostic and Statistical Manual of Mental Disorders, ed 4. Washington, American Psychiatric Association, 1994.

15 Folstein MF, Folstein SE, McHugh PR: 'Minimental state': a practical method for grading the cognitive state of patients for the clinician. J Psychiatr Res 1975;12:189-198.

16 Rosen WG, Mohs RC, Davis KL: A new rating scale for Alzheimer's disease. Am J Psychiatry 1984;141:1356-1364.

-17 Hughes CP, Berg L, Danziger WL, Coben LA, Martin RL: A new clinical scale for the staging of dementia. Br J Psychiatry 1982; 140:566-572.
18 Katz S, Ford AB, Moskowitz RW, Jackson BA, Jaffe MW: Studies of illness in the aged. The Index of ADL: a standardized measure of biological and psychosocial function. JAMA 1963;185:914-919.

19 Lawton MP, Brody EM: Assessment of older people: self-maintaining and instrumental activities of daily living. Gerontologist 1969; 9:179-186.

20 Cummings JL, Mega M, Gray K, RosenbergThompson S, Carusi DA, Gornbein J: The Neuropsychiatric Inventory: comprehensive assessment of psychopathology in dementia. Neurology 1994;44:2308-2314.

21 Guigoz Y, Vellas B, Gary PJ: The Mini Nutritional Assessment: a practical assessment tool for grading the nutritional state of elderly patients. Facts Res Gerontol 1994;Suppl 2:15-59.

22 Zarit SH, Reever KE, Bach-Peterson J: Relatives of the impaired elderly: correlates of feelings of burden. Gerontologist 1980;20: 649-655.

23 Allison PD: Survival Analysis Using the SAS System: A Practical Guide. Cary, SAS Institute, 1995, pp 158-161.

24 Zunzunegui MV, Beland F, GutierrezCuadra P: Loss to follow-up in a longitudinal study on aging in Spain. J Clin Epidemiol 2001;54:501-510.

25 Beckett LA, Brock DB, Lemke JH, Mendes de Leon CF, Guralnik JM, Fillenbaum GG, Branch LG, Wetle TT, Evans DA: Analysis of change in self-reported physical function among older persons in four population studies. Am J Epidemiol 1996;143:766-778.

26 Deeg DJ, van Tilburg T, Smit JH, de Leeuw ED: Attrition in the Longitudinal Aging Study Amsterdam: the effect of differential inclusion in side studies. J Clin Epidemiol 2002;55:319-328.

27 Schulz KF, Grimes DA: Sample size slippages in randomised trials: exclusions and the lost and wayward. Lancet 2002;359:781-785.

-28 Kristman V, Manno M, Cote P: Loss to follow-up in cohort studies: how much is too much? Eur J Epidemiol 2004;19:751-760.
29 Hayden JA, Cote P, Bombardier C: Evaluation of the quality of prognosis studies in systematic reviews. Ann Intern Med 2006;144: 427-437.

-30 Doody R, Pavlik V, Massman P, Kenan M, Yeh S, Powell S, Cooke N, Dyer C, Demirovic J, Waring S, Chan W: Changing patient characteristics and survival experience in an Alzheimer's center patient cohort. Dement Geriatr Cogn Disord 2005;20:198-208.

31 Birks J: Cholinesterase inhibitors for Alzheimer's disease. Cochrane Database Syst Rev 2006;1:CD005593.

32 Andrieu S, Balardy L, Gillette-Guyonnet S, Bocquet H, Cantet C, Albarede JL, Vellas B, Grand A: Burden experienced by informal caregivers assisting Alzheimer's patients in the REAL.FR study (in French). Rev Méd Interne 2003;24(suppl 3):351s-359s.

-33 Brodaty H, Griffin D, Hadzi-Pavlovic D: A survey of dementia carers: doctors' communications, problem behaviours and institutional care. Aust NZ J Psychiatry 1990;24: 362-370.

$>34$ Karlawish JH, Casarett D, Propert KJ, James BD, Clark CM: Relationship between Alzheimer's disease severity and patient participation in decisions about their medical care. J Geriatr Psychiatry Neurol 2002;15:68-72.

-35 Robinson KA, Dennison CR, Wayman DM, Pronovost PJ, Needham DM: Systematic review identifies number of strategies important for retaining study participants. J Clin Epidemiol 2007;60:757, e751-e757, e719.

36 de Graaf R, Bijl RV, Smit F, Ravelli A, Vollebergh WA: Psychiatric and sociodemographic predictors of attrition in a longitudinal study: The Netherlands Mental Health Survey and Incidence Study (NEMESIS). Am J Epidemiol 2000;152:1039-1047.

$\checkmark 37$ Matthews FE, Chatfield M, Freeman C, McCracken C, Brayne C: Attrition and bias in the MRC cognitive function and ageing study: an epidemiological investigation. BMC Public Health 2004;4:12. 